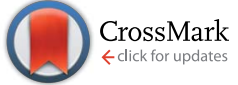

Cite this: RSC Adv., 2014, 4, 61698

Received 9th October 2014

Accepted 10th November 2014

DOI: 10.1039/c4ra12073f

www.rsc.org/advances

\section{Water-soluble non-polymeric electrospun cyclodextrin nanofiber template for the synthesis of metal oxide tubes by atomic layer deposition $\uparrow$}

\author{
Asli Celebioglu, ab Sesha Vempati, ${ }^{\text {aa }}$ Cagla Ozgit-Akgun, ${ }^{\text {ab }}$ Necmi Biyikli ${ }^{\text {ab }}$ \\ and Tamer Uyar*ab
}

\begin{abstract}
We report on the suitability of water-soluble non-polymeric electrospun cyclodextrin (CD) nanofiber templates by using atomic layer deposition (ALD) to yield metal oxide tubes. To demonstrate this, watersoluble electrospun $C D$ nanofibers were chosen as template to produce metal oxide tubes where we have tested two examples of ALD coatings, namely, $\mathrm{Al}_{2} \mathrm{O}_{3}$ and $\mathrm{ZnO}$. After the ALD coating on the CD nanofibers, the $C D$ core is simply dissolved in water to yield metal oxide tubes. Morphological investigations suggested that $\mathrm{Al}_{2} \mathrm{O}_{3}$ is smoother in contrast to $\mathrm{ZnO}$ which shows a grainy structure. Structural characterization evidenced amorphous $\mathrm{Al}_{2} \mathrm{O}_{3}$ and highly crystalline $\mathrm{ZnO}$. Given the applicability of $\mathrm{Al}_{2} \mathrm{O}_{3}$ and $\mathrm{ZnO}$ in various contexts the ionic states of $\mathrm{Al}, \mathrm{Zn}$ and $\mathrm{O}$ are also investigated. After the washing step to remove the $\mathrm{CD}$ core, $\mathrm{Al}_{2} \mathrm{O}_{3}$ developed some hydroxylation, while $\mathrm{ZnO}$ hosts various oxygen related functional groups.
\end{abstract}

\section{Introduction}

Nanostructures produced while combining industrially applicable techniques such as electrospinning and atomic layer deposition (ALD) are quite attractive as perused by various researchers for potential applications. ${ }^{1-10}$ In fact ALD can yield

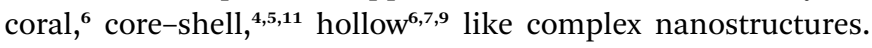
Although various polymers are the subjects of electrospinning, the compatibility between the polymer and the ALD precursor is vital. $^{2}$ The foremost condition is the thermal stability of the polymer as ALD generally takes places at slightly elevated temperatures. The other factor is the chemical compatibility, see the ALD of $\mathrm{Al}_{2} \mathrm{O}_{3}$ on nylon-6 polymer, ${ }^{2} \mathrm{ALD}$ of $\mathrm{ZnO}$ on poly(propylene) fibers with $\mathrm{Al}_{2} \mathrm{O}_{3}$ base layer to inhibit the diffusion of diethylzinc (DEZn) into the polymer. ${ }^{1}$ Despite of these limitations fibers of various polymers are explored by our group $^{\mathbf{3 , 4 , 1 2}}$ and other researchers in ALD..$^{\mathbf{1 , 2 , 6 , 7 , 9 , 1 0}} \mathrm{Viz}$. poly(propylene) $/ \mathrm{Al}_{2} \mathrm{O}_{3} / \mathrm{ZnO},{ }^{1}$ poly(acrylonitrile)/ZnO, ${ }^{\mathbf{3}, 10}$ polysulfone/ $\mathrm{ZnO},{ }^{4}$ nylon $6,6 / \mathrm{ZnO},{ }^{12}$ nylon-6/ZnO $/ \mathrm{Al}_{2} \mathrm{O}_{3},{ }^{2}$ poly(vinyl alcohol) (PVA) $/ \mathrm{Al}_{2} \mathrm{O}_{3}{ }^{6,7}$ polyvinyl acetate/ZnO. ${ }^{9}$ Although electrospun polymeric nanofibers/ALD is established in the literature, the same combination with non-polymeric nanofibers is certainly

${ }^{a}$ UNAM-National Nanotechnology Research Center, Bilkent University, Ankara, 06800, Turkey.E-mail: svempati01@qub.ac.uk; uyar@unam.bilkent.edu.tr

${ }^{b}$ Institute of Materials Science and Nanotechnology, Bilkent University, Ankara, 06800, Turkey

$\dagger$ Electronic supplementary information (ESI) available: Output results of XRD peak deconvolution, results of XPS survey scan and $\mathrm{Zn} 2 \mathrm{p}$ core-level XPS. See DOI: $10.1039 / \mathrm{c} 4 \mathrm{ra12073f}$ novel and potential. In the context of electrospinning of nonpolymeric systems, cyclodextrin $(\mathrm{CD})^{13-16}$ are quite interesting apart from others. ${ }^{17,18}$ Hydrogen-bond-mediated aggregates of CD molecules help the electrospinning process where the aggregation is analogous to the polymeric chain entanglement. These CD aggregates are big enough to mimic the entanglement so that a continuous non-woven nanofibrous mat can be obtained..$^{13-16}$ Hence in this study we demonstrate the potential compatibility of CD nanofibers in ALD process while exploiting its fascinating properties. For instance, the intrinsic nature of CD helps in sustaining the fiber structure until $\sim 150{ }^{\circ} \mathrm{C}$, a typical temperature for an ALD process. This is in contrast to water-soluble polymers such as PEO which has melting point of $\sim 65{ }^{\circ} \mathrm{C}$ or PVA with a glass transition temperature less than $100{ }^{\circ} \mathrm{C}$. Hence the present combination is quite potential to produce metal oxide tubes for various applications, especially sensors. ${ }^{9,10}$ Basically, after the ALD process the core-shell fiber structure is either subjected to calcination ${ }^{9,7}$ or dissolution ${ }^{6}$ to remove the core-polymer yielding tube structure. Dissolution of the 'core' is quite interesting and energy efficient in contrast to the calcination, while on the other hand the latter strongly manipulates the crystalline property of the shell material. Hence it is always encouraging to increase the applicability of water processible materials by ever increasing environmental and cost related issues (green chemistry). Particularly, CDs are non toxic materials and hence their release into the environment (after the washing step) does not cause any loading. When compared to the polymeric systems, the CD nanofibers have relatively higher and rapid solubility with small molecular size which enables a better removal from core-shell structure. 
Furthermore, prolonged exposure of metal oxide surfaces to solvents can influence the surface chemical characteristics. We do acknowledge that water-soluble polymers such as $\mathrm{PVA}^{6}$ fiber template has been used to obtain $\mathrm{Al}_{2} \mathrm{O}_{3}$ tubes via ALD process however, not many other reports are seen. This study is significant in terms of employing a non-polymeric template as well as demonstrating the compatibility with ALD process to produce metal oxide tubes.

In this report we adopted this combination to produce coreshell structured CD-metal oxide fibers and subsequently they were subjected to washing which removes the CD core. Among various nanostructures, tubes have attracted a lot of attention due to their potential applicability. We have used methyl- $\beta$ cyclodextrin (M $\beta \mathrm{CD})$ and hydroxypropyl- $\beta$-cyclodextrin (HP $\beta C D)$ for the electrospinning since they have a very high solubility when compared to native $\beta$-CD. We use these electrospun $\mathrm{CD}$ nanofibers as templates to obtain $\mathrm{Al}_{2} \mathrm{O}_{3}$ and $\mathrm{ZnO}$ tubes by ALD coating where the core-shell structure is subjected to a simple dissolution of CD core.

\section{Experimental}

\section{Materials}

HP $\beta C D$ (molar substitution 0.6) and M $\beta C D$ (molar substitution 1.6-1.9) were purchased from Wacker Chemie AG, Germany. $N, N$-dimethylformamide (DMF) was purchased from Riedel, Pestenal. Trimethylaluminum (TMAl) and diethylzinc (DEZn) were procured from Sigma Aldrich and HPLC-grade deionized water were used for the ALD process. All the materials were used without any purification.

\section{Fabrication of metal oxide tubes}

The process of obtaining metal oxide tubes consists of three steps. Initially CD nanofibers are produced (Step 1, electrospinning), followed by the deposition of metal oxide (Step 2, ALD process). Finally in Step 3, the core-shell nanofibers are subjected to washing, which removes the CD 'core'. Crucial points related to Step 1, 2 and 3 are discussed in the context of Fig. 1.

Step 1. Clear and homogenous solutions of $M \beta C D$ and HP $\beta C D$ were prepared at $160 \%(w / v)$ and $120 \%(w / v)$ in DMF, respectively. Each of these solutions was taken in a syringe and a metallic needle of $0.45 \mathrm{~mm}$ inner diameter is attached as a tip. The syringe was placed horizontally on a syringe pump (SP 101IZ, WPI). A high voltage (Matsusada Precision, AU Series) terminal was connected to the tip while the counter electrode covered with an Al foil (substrate) was grounded. The electrospinning of the CD solutions was performed with the following parameters: applied voltage $\sim 15 \mathrm{kV}$, tip-to-collector distance 10-15 $\mathrm{cm}$ and the solution flow rate was kept at $0.5 \mathrm{~mL} \mathrm{~h}^{-1}$. The electrospinning apparatus was enclosed in a box at $25{ }^{\circ} \mathrm{C}$ and $30 \%$ relative humidity. These electrospun nanofibers of $\mathrm{HP} \beta C D$ or $\mathrm{M} \beta \mathrm{CD}$ are used as substrates for subsequent deposition of $\mathrm{Al}_{2} \mathrm{O}_{3}$ or $\mathrm{ZnO}$.

Step 2. In this step electrospun $\mathrm{CD}$ nanofibers were coated either with $\mathrm{Al}_{2} \mathrm{O}_{3}$ or $\mathrm{ZnO}$ at $80{ }^{\circ} \mathrm{C}$ in a Savannah S100 ALD

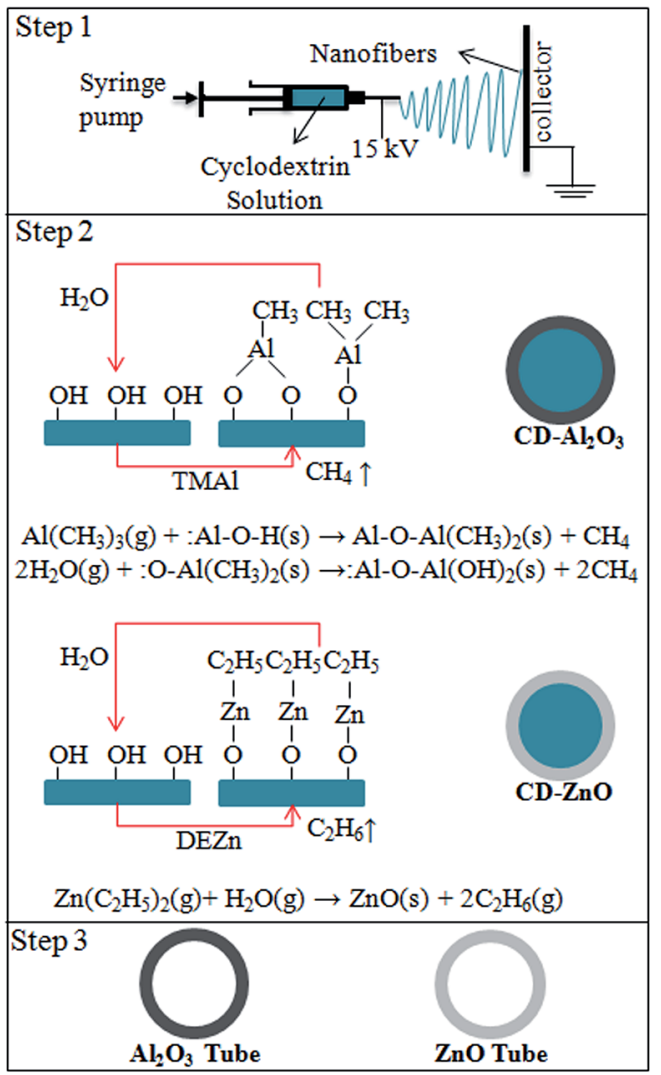

Fig. 1 Schematic diagram showing the three step process to fabricate the metal oxide tubes and the mechanism involved in the ALD process.

reactor (Cambridge Nanotech Inc.) with $\mathrm{N}_{2}$ as a carrier gas. Depositions were performed with exposure mode (a trademark of Ultratech/Cambridge Nanotech Inc.) in which dynamic vacuum is switched to static vacuum just before each precursor pulse by closing the valve between the reaction chamber and the pump. This allows the substrate to be exposed to precursor molecules for a certain period of time (i.e., exposure time). This is followed by a purging period, where the chamber is switched back to dynamic vacuum for efficient evacuation/purging of excess precursor molecules and gaseous byproducts. 200 cycles $\mathrm{Al}_{2} \mathrm{O}_{3}$ or 400 cycles $\mathrm{ZnO}$ were deposited, where one ALD cycle consists of the following steps. Valve $\mathrm{OFF} / \mathrm{N}_{2}$ flow set to $10 \mathrm{sccm} /$ TMAl or DEZn pulse $(0.015 \mathrm{~s})$ /exposure $(60 \mathrm{~s}) /$ valve $\mathrm{ON} / \mathrm{N}_{2}$ flow set to $20 \mathrm{sccm} / \mathrm{N}_{2}$ purge $(60 \mathrm{~s}) /$ valve $\mathrm{OFF} / \mathrm{N}_{2}$ flow set to $10 \mathrm{sccm} /$ $\mathrm{H}_{2} \mathrm{O}$ pulse $(0.015 \mathrm{~s}) /$ exposure $(60 \mathrm{~s}) /$ valve $\mathrm{ON} / \mathrm{N}_{2}$ flow set to 20 $\mathrm{sccm} / \mathrm{N}_{2}$ purge (60 s).

Step 3. At this stage, we remove the CD core by washing the $\mathrm{Al}_{2} \mathrm{O}_{3}$ or $\mathrm{ZnO}$ coated core-shell nanofibers in water for $45 \mathrm{~min}$ with occasional manual shaking. These core-shell and tube structures were subjected to thorough characterization. For easy reference of various samples the following abbreviations are used in this report. 200 cycles of $\mathrm{Al}_{2} \mathrm{O}_{3}$ on $\mathrm{M} \beta C D$ nanofibers is refered as AM2, while 400 cycles of $\mathrm{ZnO}$ on $\mathrm{HP} \beta \mathrm{CD}$ nanofibers is referred as ZH4. Samples subjected to washing are abbreviated as AM2_W or ZH4_W. Other samples follow similar nomenclature. 


\section{Characterization}

A scanning electron microscope (SEM, FEI-Quanta 200 FEG) was employed to investigate the morphology and dimensions of the samples before and after the washing step. Nominal $5 \mathrm{~nm} \mathrm{Au/Pd}$ was sputtered on the samples prior to the observation under SEM. Average fiber diameter (AFD) was estimated from SEM images with samplings well above the statistically acceptable limit. Metal oxide tubes were subjected to transmission electron microscopy (TEM, FEI-Tecnai G2 F30) measurements where the sample was dispersed in ethanol and a tiny droplet was analyzed from a holey carbon coated TEM grid. X-ray diffraction (XRD) patterns were recorded in the range of $2 \theta=10-90^{\circ}$ using PANalytical X'Pert Pro Multi Purpose X-ray diffractometer with $\mathrm{Cu} \mathrm{K} \alpha$ radiation $(\lambda=1.5418 \AA$ ) $)$. The ionic states of the constituent elements at the surface of the samples (400 $\mu \mathrm{m}$ spot size) were investigated by X-ray photoelectron spectroscopy (XPS, Thermoscientific K-Alpha, Al K $\alpha$ radiation with $h \nu=1486.6 \mathrm{eV}$ ) with a flood gun charge neutralizer. For the core-level spectra, the pass energy and step size were set to $30 \mathrm{eV}$ and $0.1 \mathrm{eV}$, respectively. Valence band (VB) spectra were also recorded with a pass energy of $30 \mathrm{eV}$ in energy steps of $0.2 \mathrm{eV}$. Spectral deconvolutions of the XPS data were performed through Avantage software while considering the chemistry of the sample. Origin 8.5 has been employed to deconvolute the XRD peaks with Lorentzian function. In the case of XRD, number of peaks and their angular location were the initial values while other parameters are set as free until convergence.

\section{Results and discussion}

As outlined in the introduction, electrospinning is a quite potential technique to produce polymeric and non-polymeric nanofibers (Fig. 1, Step 1). When a polymer is subjected to electrospinning, the overlap and entanglement of the polymeric chains is essential for the electrospinning process. Analogous to this, CD molecules form 'aggregates' which fulfil the essential criteria of electrospinning process. These aggregates are accelerated in the electric field and rapidly solidify while reaching the substrate in the form of nanofibers. ${ }^{13}$

Basically in an ALD process gaseous precursors are injected with a carrier gas into a chamber (containing the substrate) at a predetermined flow rate in a sequential manner. Precursor molecules are first adsorbed on the surface and then eventually chemisorbed by the reactive surface sites, forming a monomolecular layer of that precursor. In the case of $\mathrm{Al}_{2} \mathrm{O}_{3},-\mathrm{CH}_{3}$ ligands in the TMAl interact with the surface as shown in Fig. 1, Step 2 (top). Note that we did not show the O bridge bonds. The remnant methyl groups of TMAl react with the next pulse of $\mathrm{H}_{2} \mathrm{O}$. The sequence of reaction mechanism is shown on the image (Fig. 1). Note that the $-\mathrm{CH}_{3}$ ligands may interact with some other active functional groups if $-\mathrm{OH}$ groups are not available. If not the growth process stops until the next pulse of precursor $\left(\mathrm{H}_{2} \mathrm{O}\right)$ arrives. In the case of $\mathrm{CD}$ no pre-treatment is applied in the ALD process, as the CD molecules have sufficient density of $-\mathrm{OH}$ groups. Each CD molecule consists of $\sim 20$ and $\sim 9-\mathrm{OH}$ groups for $\mathrm{HP} \beta \mathrm{CD}$ and $\mathrm{M} \beta \mathrm{CD}$, respectively. However, if the reaction requires $-\mathrm{OH}$ mediation and if the surface lacks it then a pre-treatment with water vapor is generally applied. Most importantly the chemisorption of TMAl has to take place as one monomolecular layer on the sample surface. The surface chemical functionality of $\mathrm{CD}$ is quite interesting when compared to polymers those were subjected to ALD processing, because of the surface -OH groups. For ZnO deposition, DEZn also reacts similarly with the $\mathrm{H}_{2} \mathrm{O}$ molecules as shown in Fig. 1, Step 2 (bottom). Initially DEZn molecules arrive at the surface and form a surface bond with the $-\mathrm{OH}$ groups. When $\mathrm{H}_{2} \mathrm{O}$ is pulsed into the chamber the second ethyl group forms $\mathrm{C}_{2} \mathrm{H}_{6}$ gas leaving - $\mathrm{OH}$ groups behind. The reaction mechanism is shown on the image (Fig. 1, bottom of Step 2). The surface functional groups of $\mathrm{CD}$ can be considered as an additional advantage in the ALD process.

The representative SEM images of pristine and ALD treated CD nanofibers (before and after washing step) are shown in Fig. 2. It was observed that ALD process did not cause any disruption to the nanofiber morphology. It is interesting to note that the AFD decreases when the core-shell nanofibers are subjected to calcination to remove the polymeric core while the percentage shrinkage depends on the type and morphology of the polymer. ${ }^{5}$ On contrary, for the case of washing, we may not expect a change in the AFD. Severe morphological changes can occur when the nanofibers are subjected to thermal treatments. ${ }^{3,5}$ Once the 'core' is washed the resulting tube-like structure is apparent for all cases. In Fig. $2 \mathrm{~d}, \mathrm{~h}, \mathrm{f}$ and $\mathrm{j}$ the metal oxide coating is thin enough to be electron-transparent as the tubes from the bottom layers are explicit. In Fig. $2 \mathrm{f}$ we show a selected region displaying their tube-like structures.

We have analyzed the diameters of samples after $\mathrm{Al}_{2} \mathrm{O}_{3}$ or $\mathrm{ZnO}$ coating for both the types of CD nanofibers. The results are plotted in Fig. 3 with Gaussian fittings. The center of the peak is numerically denoted on the corresponding graph. The process of fiber formation in electrospinning is quite complex and obtaining uniform morphology and diameter is a rather hard task. ${ }^{19-22}$ Similar to the case of polymeric fibers, the homogeneity and diameter of non-polymeric CD nanofibers highly depend on the used solvent types and concentration of the system..$^{\mathbf{1 3} 14}$ In our previous studies, ${ }^{\mathbf{1 3 , 1 4}}$ the electrospinning parameters were optimized for both $\mathrm{CD}$ types to produce nanofibers having bead-free morphology, thus we were able to obtain uniform tube structures in this study. However there is a variance at the diameter distributions and this is because of the intrinsic nature of the electrospinning process. On the other hand, after the washing step the structural integrity of the nanofibers was preserved yielding metal oxide tubes.

Local crystal structure and the thickness of the shell coating can be precisely estimated by recording TEM images on the samples. We have used tube-form of samples for such measurements and typical images are shown in Fig. 4. 200 cycles of $\mathrm{Al}_{2} \mathrm{O}_{3}$ resulted in a thickness of $\sim 20 \mathrm{~nm}, 400$ cycles of ZnO has developed a thickness of $\sim 40 \mathrm{~nm}$. Samples AM2_W and AH2_W generally have a smoother morphology when compared to those of $\mathrm{ZM} 4$ _W and $\mathrm{ZH} 4$ _W samples. The smoother morphology is convincing as $\mathrm{Al}_{2} \mathrm{O}_{3}$ did not depict any grainy structure while in contrast $\mathrm{ZnO}$ has shown well 

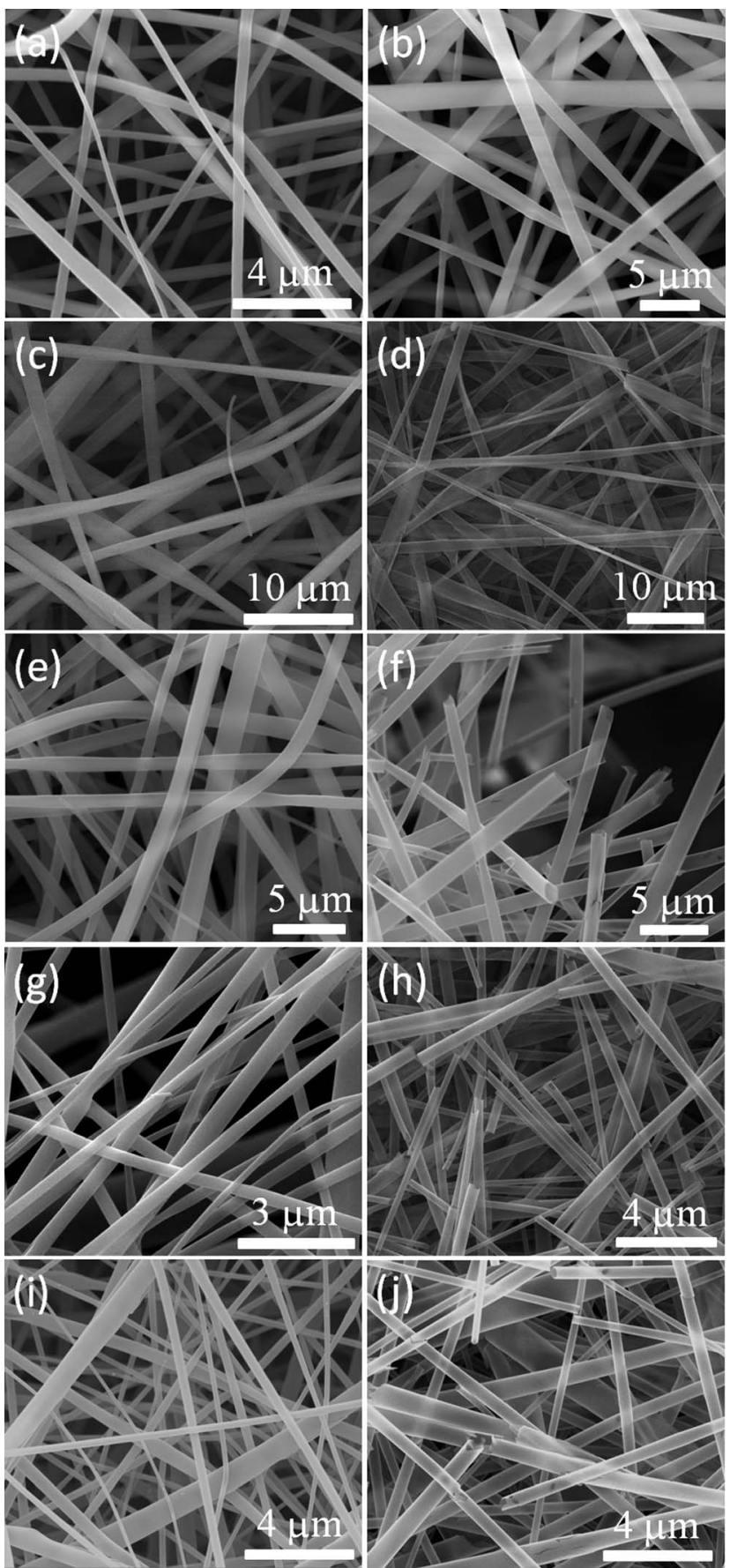

Fig. 2 SEM images of samples before and after washing steps. (a) $M \beta C D$ nanofibers, (b) HPBCD nanofibers (c) AM2, (d) AM2_W, (e) AH2, (f) $\mathrm{AH} 2 \_$W, (g) ZM2, (h) ZM2_W, (i) ZH4, and (j) ZH4_W.

developed grains. STEM (dark field) image is shown in Fig. 4b for AH4_W sample, where we explicitly see the tube-like structure. As expected ZM4_W and ZH4_W samples have shown welldeveloped crystal grains as seen in Fig. 4c and d for hollow, respectively. The grain boundaries can host oxygen-related functional groups, which are deterministic in the optical properties ${ }^{23-25}$ photocatalysis, ${ }^{3-5}$ photoresponse ${ }^{23}$ etc. The electron diffraction pattern is shown for ZH4_W sample (inset of Fig. 4d) with the corresponding reflections annotated. These

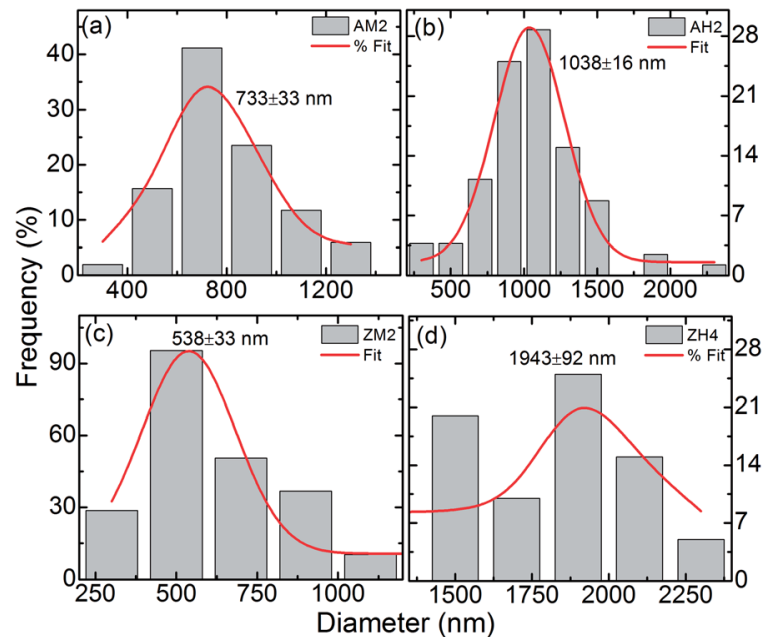

Fig. 3 Diameter distribution and the AFD of samples from SEM images. (a) AM2, (b) AH2, (c) ZM2, and (d) ZH4. The center of Gaussian peak (i.e., average fiber diameter) is annotated on each of the distributions.

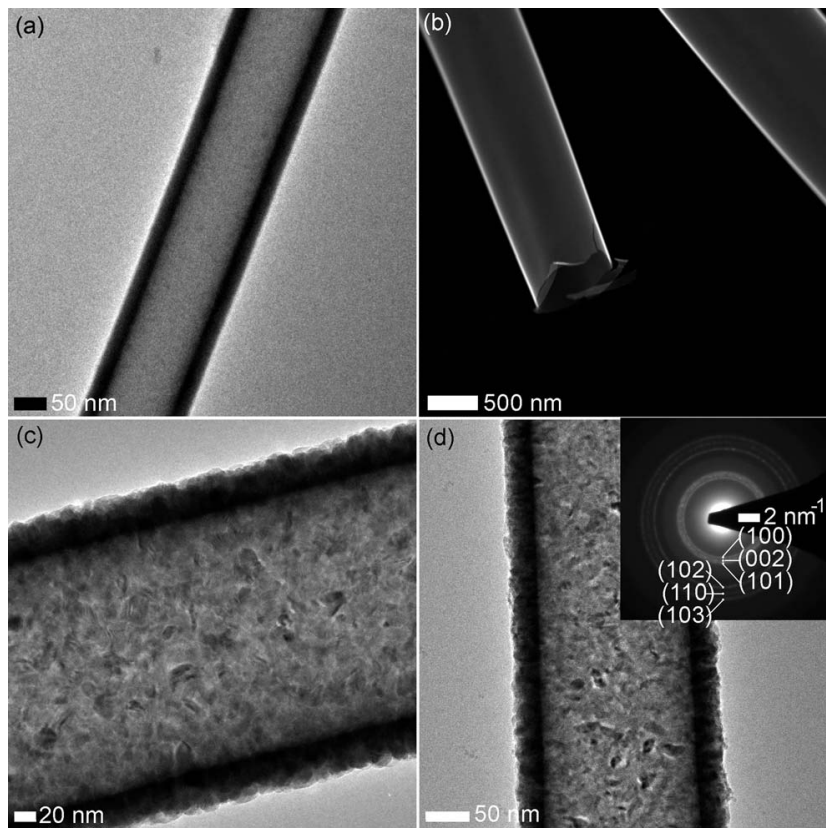

Fig. 4 TEM of images of (a) AM2_W, (b) AH2_W, (c) ZM4_W, and (d) ZH4_W. The inset shows ED from $\mathrm{ZH} 4$.

circular rings seen in the pattern consists of a series of dots representing the well-developed single crystals assembled in various directions. The pattern is found to be consistent with the literature..$^{24,25}$

XRD patterns form ZM2, ZH4 and their washed counterparts are shown in Fig. 5. AH2, AM2 and their tube counterparts did not depict any clear diffraction peaks in the XRD analysis (not shown here). In contrast to $\mathrm{Al}_{2} \mathrm{O}_{3}$ case, explicit peaks were observed from $\mathrm{ZnO}$ and the corresponding reflections were annotated on Fig. 5. We have compared the characteristics (Table 1 of ESI $\dagger$ ) of deconvoluted peaks $\left(30-39^{\circ}\right)$ for $\mathrm{ZnO}$ 

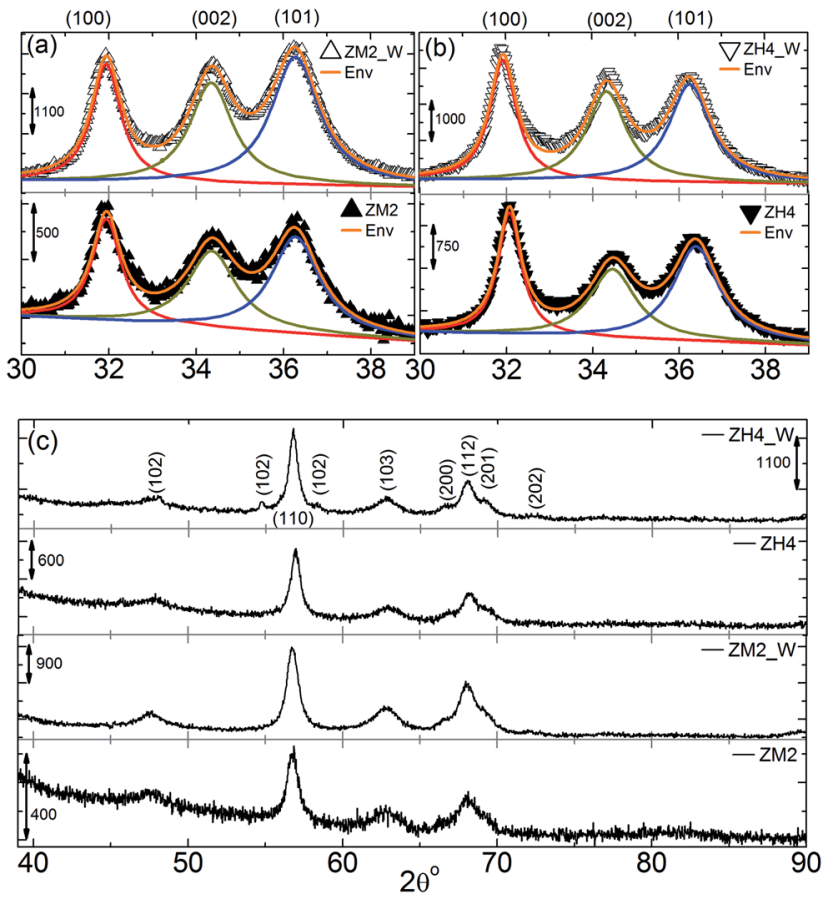

Fig. 5 XRD patterns of ALD processed $(\mathrm{ZnO})$ samples before and after washing steps. (a) ZM2, ZM2_W, (b) ZH4, ZH4_W within 30-39 and depicting the deconvolution of three reflections, viz. (100), (002) and (101), and (c) $39-90^{\circ}$ range is shown for the above samples.

samples (ZM2, ZM2_W, ZH4, and ZH4_W) in terms of angular position and full width at half maximum (FWHM). Importantly, the values from Table 1 of ESI $\uparrow$ suggest that the washing away the 'core' did not induce any strain in the lattice. As mentioned in the introduction, thermal treatment can also be employed to remove the 'core'. In the case of calcination there can be a residual strain development, which is clearly not the case here. When the $-\mathrm{OH}$ groups of $\mathrm{CD}$ are randomly substituted with methoxy groups (M $\beta C D)$ and hydroxypropyl (HP $\beta C D)$, it results in amorphous material depicting a broad diffraction peak ( $2 \theta$ range not shown here) in contrast to pure $\beta-\mathrm{CD}$ which is a crystalline material. ${ }^{13,14}$

Ionic state of elements on the surface can be identified rather precisely by analyzing XPS spectra. It is important in various contexts, for example $\mathrm{Al}_{2} \mathrm{O}_{3}$ can be used as an anticorrosive coating, where a clear understanding of the surface chemical functionalities is required. ${ }^{26}$ While the surface characterization of the wide band gap material such as $\mathrm{ZnO}$ is of prime importance in the context of optical properties, ${ }^{23-25}$ photocatalysis, ${ }^{3-5}$ photoresponse ${ }^{23}$ etc. XPS survey scan (not shown here) is performed on all samples and the results from metal oxide tubes are tabulated in Table 2 of ESI. $\dagger$ Core level XPS spectra were analyzed on $\mathrm{Al}, \mathrm{Zn}$ and $\mathrm{O}$ elements for all four cases before and after the washing step to infer any chemical changes occurred on the surface. Al2p spectra were shown in Fig. $6 \mathrm{a}$ and $\mathrm{b}$ from $\mathrm{Al}_{2} \mathrm{O}_{3}$ samples of $\mathrm{AM} 2, \mathrm{AH} 2$ and their hollow counterparts, respectively. A significant signal-to-noise ratio is obtained despite of the relatively low ionization cross-section of $\mathrm{Al}^{27}$ The energetic values of Al2p doublet (2p3/2 and 2p1/2) are

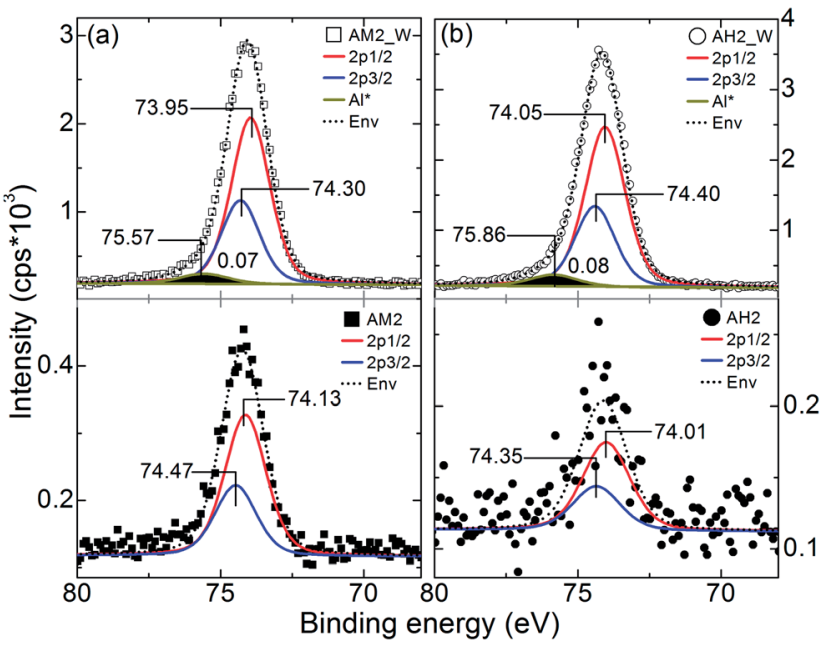

Fig. 6 Al core level XPS spectra from $\mathrm{Al}_{2} \mathrm{O}_{3}$ coated samples before and after washing steps, (a) AM2, AM2_W and (b) AH2, AH2_W. The peak positions are annotated on the image in $\mathrm{eV}$. The area ratio of the peak corresponding to hydroxyl bonded $\mathrm{Al}$ is annotated for washed samples.

not only in line with literature but also comparable across the $\mathrm{Al}_{2} \mathrm{O}_{3}$ coated samples. ${ }^{28}$ However in the case of metal oxide tubes, a high energy component is seen for AM2_W $(75.57 \mathrm{eV})$ and AH2_W $(75.86 \mathrm{eV})$ cases which might be attributed to the surface bound hydroxyl groups on $\mathrm{Al} .{ }^{28}$ The surface groups arose from 'Step 3' during the fabrication of tubes. In the case of $\mathrm{ZnO}$, ZM2 and ZH4 samples and their tube counterparts did not depict any differences in the Zn2p core-level spectra (Fig. 1 of ESI†). The spectral locations of the peaks are in line with literature. ${ }^{25}$ Not observing any differences in $\mathrm{Zn} 2 \mathrm{p}$ core-level spectra, of course, does not rule out the possibility of surface hydroxide formation or the presence of oxygen-related functional groups. We will see that this is the case in the context of O1s spectra from $\mathrm{ZnO}$ samples.

In the following we discuss the O1s core level spectra for $\mathrm{Al}_{2} \mathrm{O}_{3}$ and $\mathrm{ZnO}$ coatings from core-shell and metal oxide tubes. O1s spectra were shown in Fig. $7 \mathrm{a}$ and $\mathrm{b}$ from $\mathrm{Al}_{2} \mathrm{O}_{3}$ samples of $\mathrm{AM} 2, \mathrm{AH} 2$ and their tube counterparts, respectively. All the spectra were deconvoluted according to the chemistry of the material. The peak corresponding to lattice oxygen in each of the materials is shown as a shaded area in the plots. The spectra from AM2 an AH2 have shown major peaks centered at $\sim 531 \mathrm{eV}$ corresponding to the oxygen in $\mathrm{Al}_{2} \mathrm{O}_{3}\left(\mathrm{O}_{\mathrm{Al}_{2} \mathrm{O}_{3}}\right)$ and are consistent with the literature. ${ }^{28}$ The other minor peak appeared at $\sim 529.5$ $\mathrm{eV}$ for $\mathrm{AM} 2$ and $\mathrm{AH} 2$ samples, might be originated from contaminants while transporting the sample. The second peak on the higher binding energy (BE) side $(\sim 533 \mathrm{eV})$ is attributed to adsorbed $\mathrm{H}_{2} \mathrm{O}\left(\mathrm{O}_{\mathrm{H}_{2} \mathrm{O}}\right)$., ${ }^{4,5}$ Significant changes were observed for tube samples after 'Step 3', AM2_W and AH2_W where O1s spectra consist of four peaks (top parts of Fig. 7a and b). Importantly the peaks at $\sim 531 \mathrm{eV}$ are from the $\mathrm{O}_{\mathrm{Al}_{2} \mathrm{O}_{3}}$ (shaded). While the peaks at $\sim 533 \mathrm{eV}$ are from $\mathrm{O}_{\mathrm{H}_{2} \mathrm{O}}$ and those at $\sim 530 \mathrm{eV}$ are from differential charging (Diff). Differential charging generally occurs on the surface because of the localized 


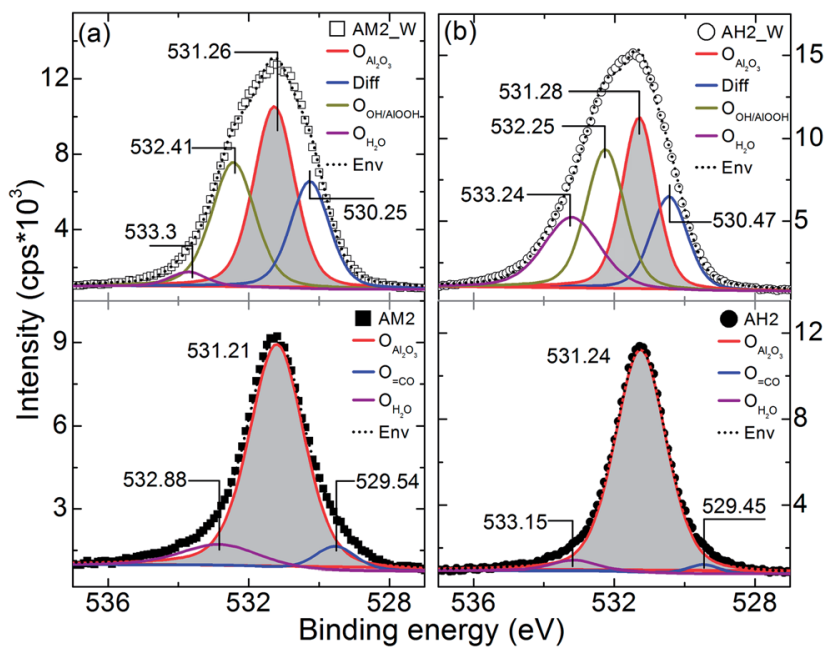

Fig. 7 O1s core level XPS spectra from $\mathrm{Al}_{2} \mathrm{O}_{3}$ coated electrospun samples before and after washing steps, (a) AM2, AM2_W and (b) AH2, $\mathrm{AH} 2$ _W. The peak positions are annotated on the plot in $\mathrm{eV}$.

differences in the charge state. ${ }^{28}$ Especially the mixture of $\mathrm{Al}_{2} \mathrm{O}_{3}$ and $\mathrm{AlOOH}$ phases perhaps enhance such possibility. Also because of the washing step, prominent peak appeared around $532 \mathrm{eV}$ corresponds to $\mathrm{O}$ in $\mathrm{OH}$ of $\mathrm{AlOOH}$ for AM2_W and AH2_W samples. ${ }^{28}$

O1s spectra from ZM2, ZH4 and their tube counterparts were shown in Fig. 8. All the spectra were deconvoluted into three peaks and the origin for each of them is discussed contextually. The peak corresponding to lattice oxygen from each of the materials is shaded in all cases. As mentioned earlier, the photocatalytic activity depends on the ionic state of the chemisorbed surface oxygen..$^{3-5} \mathrm{O} 1 \mathrm{~s}$ spectra were shown in Fig. 8a and $\mathrm{b}$ from $\mathrm{ZnO}$ samples of $\mathrm{ZM} 2$, ZH4 and their tube counterparts, respectively. From Fig. 8a, the shaded peak within the range of $530.57-530.61 \mathrm{eV}$ in all samples is attributed to $\mathrm{O}^{2-}$

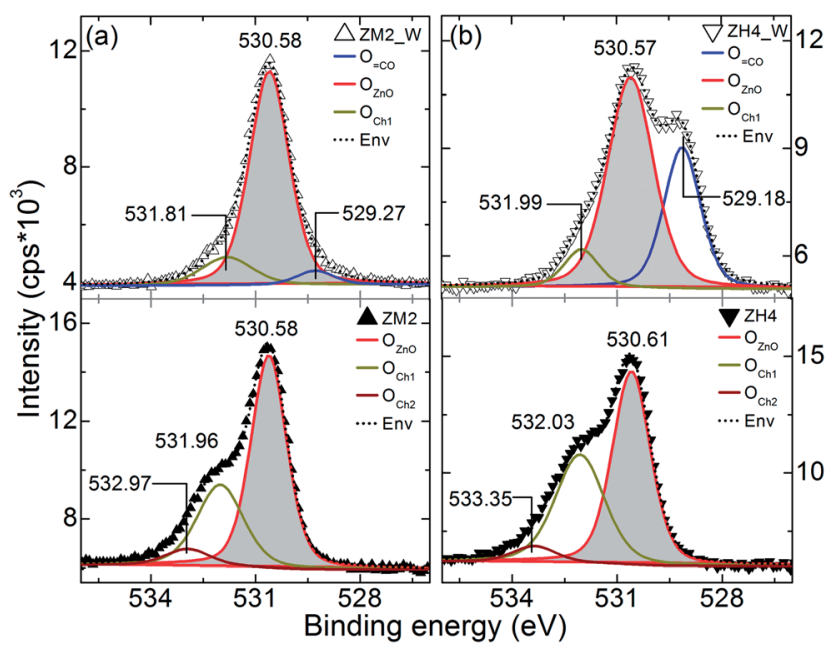

Fig. 8 O1s core level XPS spectra from samples before and after washing steps, (a) ZM2, ZM2_W and (b) ZH4, ZH4_W. The peak positions are annotated on the plot in $\mathrm{eV}$. ions in the wurtzite structure which are supplemented by nearest neighbor $\mathrm{Zn}^{2+}$ in hexagonal configuration $\left(\mathrm{O}_{\mathrm{Zno}}\right)$. Apart from this, as prepared core-shell structures (ZM2 and ZH4) consist of two more peaks each on the higher $\mathrm{BE}$ side of $\mathrm{O}_{\mathrm{Zno}}$. In the case of ZM2, $531.96 \mathrm{eV}$ peak and $532.97 \mathrm{eV}$ peak are attributed to chemisorbed oxygen, $\mathrm{O}_{\mathrm{Ch} 1}$ and $\mathrm{O}_{\mathrm{Ch} 2}$ respectively. ZH4 case, 532.03 and $533.35 \mathrm{eV}$ peaks are ascribed to $\mathrm{O}_{\mathrm{Ch} 1}$ and $\mathrm{O}_{\mathrm{Ch} 2}$ respectively. Generally, the peak centered at $531.50 \pm 0.1$ $\mathrm{eV}$ is associated with $\mathrm{O}^{x-}$ ions $(x<2)$. The second high-energy minor peak at $532.50 \pm 0.1 \mathrm{eV}$ is typically ascribed to $\mathrm{OH}^{-}$ groups, chemisorbed oxygen or dissociated oxygen. ${ }^{3-5}$ This higher BE peak $(532.50 \pm 0.1 \mathrm{eV})$ is also attributed to oxygen in $-\mathrm{CO}_{3}$ by some authors. ${ }^{27,29}$ It can be seen that the relative density of chemisorbed oxygen is higher for ZH4 than ZM2. The slight variation in the energy of the peak corresponding to non-native oxygen because what we see is an integral effect of various species. On the other hand, the grain boundaries (as seen in the TEM images) are obvious locations for such oxygen-related species to chemisorb. Since the sharing of an electron can be partial when combined with the above ions it has produced relatively broad binding energies peaked at $\sim 531.9 \mathrm{eV}$.

Despite of the above discussed external oxygen content, the relative intensity of the peak corresponding to $\mathrm{ZnO}$ is the most prominent in all cases. The two non lattice origin peaks generally occur in connection to the oxygen vacancies $\left(V_{\mathrm{O}} \mathrm{S}\right)$ in the ZnO lattice. ${ }^{3-5,25}$ In other words, the relative intensities of these components can be connected to the variations in the density of $V_{\mathrm{O}} \mathrm{s} / \mathrm{chemical}$ functionalities. When the core-shell nanofibers subjected to washing step to convert into metal oxide tubes, significant changes have taken place, see ZM2_W in Fig. 8a (top). ZM2_W has shown a component at $529.27 \mathrm{eV}$ which is attributed to various contaminants. The second component $\sim 531.81 \mathrm{eV}$ from ZM2_W is attributed to chemisorbed oxygen satisfying the earlier given argument. Furthermore, the surface- $\mathrm{Zn}(\mathrm{OH})_{2}$ component might be quite low when compared to the overall $\mathrm{ZnO}$ content. Note that the hydroxide formation is limited to the surface as we did not evidence any peaks corresponding to $\mathrm{Zn}(\mathrm{OH})_{2}$ in the XRD pattern (range not shown here).

Density of occupied VB states is investigated in the case of $\mathrm{Al}_{2} \mathrm{O}_{3}$ tubes and core-shell nanofibers and significant changes were observed before and after washing. The changes are limited to the features below the edge while the edge is undisturbed. A very high band gap (O2p to Al3s transitions) of $\mathrm{Al}_{2} \mathrm{O}_{3}$ arises because of predominant ionic natured bonding. ${ }^{30}$ Experimentally obtained VB density of states (DOS) was shown in Fig. 9. The upper VB consists of two main features (enclosed with three peaks) within the given energy range. O2s arises below the $\mathrm{VB}$ maximum around $-20 \mathrm{eV}$ (range not shown here). The first feature is nonbonding orbitals of $\mathrm{O} 2 \mathrm{p}$ form the top of the upper VB (Fig. 9a). French $^{30}$ suggests that these bands are 'flat' in $k$-space and correspond to localized state in real space forming $\mathrm{O}^{2-}$ ion. Hence the VB is anionic in nature, in contrast empty $\mathrm{Al}$ antibonding orbitals corresponding to $\mathrm{Al}^{3+}$ form the cationic conduction band. ${ }^{30}$ The second feature corresponds to mixed $\mathrm{Al}$ and $\mathrm{O}$ origin. These are hybridized Al-O bonding orbitals $(h \mathrm{Al}-\mathrm{O})$ represent the covalent bonding present in 


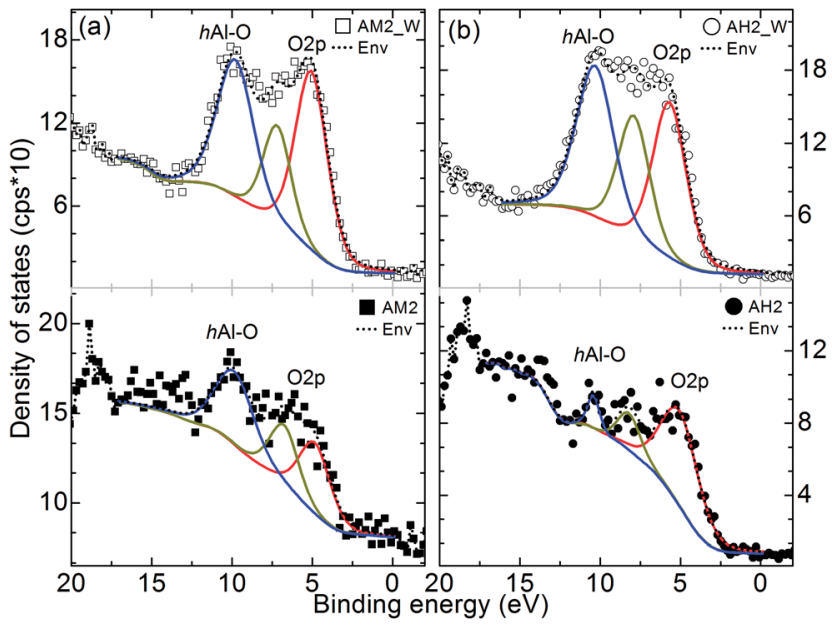

Fig. 9 Valance band spectra from $\mathrm{Al}_{2} \mathrm{O}_{3}$ coated samples before and after washing steps, (a) AM2, AM2_W and (b) AH2, AH2_W.

$\mathrm{Al}_{2} \mathrm{O}_{3}$. Furthermore, above $14 \mathrm{eV}$ a clear difference is seen for AH2 and AH2_W samples, where the former has shown relatively higher DOS in contrast to the latter. It is also notable that $\mathrm{AH} 2$ _W is more comparable to the $\mathrm{Al}_{2} \mathrm{O}_{3}$ spectrum of native or thermal oxide. ${ }^{30} \mathrm{VB}$ structure of $\mathrm{ZnO}$ is investigated and the results suggest that there are no changes in the VB edge before and after washing and $M \beta C D$ to $H P \beta C D$ nanofibers (spectra not shown here).

We have attempted to obtain $\mathrm{ZnO}$ tubes with HPßCD nanofibers with 200 cycles of deposition. However after washing the tube structure is not sustained because of the following two reasons; (1) we have evidenced that $\mathrm{HP} \beta C D$ nanofibers are relatively thicker than $M \beta C D$ nanofibers, (2) in the ALD process $\mathrm{ZnO}$ forms grain like structure. At higher diameter of core the grainy structure collapses due to the lack of mechanical robustness. Hence we have performed 400 cycles of deposition which has yielded structurally stable $\mathrm{ZH} 4$ _W sample. Note that this is not the case with $\mathrm{Al}_{2} \mathrm{O}_{3}$ which has formed amorphous structure and hence 200 cycles of deposition is good enough to sustain the structure. Hence the crystalline nature of the ALD product determines the integrity of the structure.

\section{Conclusions}

In this study we show that non-polymeric systems such as CD (M $\beta C D$ and $H P \beta C D)$ are well compatible in ALD process. This combination can produce core-shell nanofibers and subsequently metal oxide tubes. CD nanofibers are compatible at relatively higher temperatures which can have a better applicability in ALD processing. Exploiting the excellent water solubility of $\mathrm{CD}$ we have tested two metal oxide coatings viz. $\mathrm{Al}_{2} \mathrm{O}_{3}$ and $\mathrm{ZnO}$ and thoroughly characterized the core-shell nanofibers and metal oxide tubes. By considering the deposition mechanism we note that the surface $-\mathrm{OH}$ groups of $\mathrm{CD}$ are beneficial to support a uniform coating. The surface morphology examination via SEM suggested smooth and consistent morphology within each of the samples. After washing the 'core' the tube-like structure is rather explicit under SEM. TEM images have evidenced smooth morphology for $\mathrm{Al}_{2} \mathrm{O}_{3}$ and grainy structure for $\mathrm{ZnO}$. Electron diffraction confirmed the wurtzite structure of $\mathrm{ZnO}$. XRD analyses of coreshell nanofibers and $\mathrm{ZnO}$ tubes corroborate no residual stress/ strain development and wurtzite structure as well. XPS spectral analysis on $\mathrm{Al}_{2} \mathrm{O}_{3}$ and $\mathrm{ZnO}$ has confirmed the ionic state of $\mathrm{Al}$ and $\mathrm{Zn}$. Core-level XPS on $\mathrm{Al}$ has shown a small fraction of hydroxylation. O1s from $\mathrm{Al}_{2} \mathrm{O}_{3}$ has shown significant variations within core-shell and tube samples. Noticeably tube samples host AlOOH on the surface apart from other typical functional groups. O1s from $\mathrm{ZnO}$ is discussed elaborately as the grainy structure and intrinsic defects can host a variety of functional groups. Similar to the case of $\mathrm{O} 1 \mathrm{~s}$ from $\mathrm{Al}_{2} \mathrm{O}$, its $\mathrm{VB}$ structure also depicted notable differences which might arise from the formation of $\mathrm{AlOOH}$ on the surface because of the washing step.

\section{Acknowledgements}

A.C. thanks The Scientific and Technological Research Council of Turkey (TUBITAK) TUBITAK-BIDEB-2228 for PhD scholarship. S.V. thanks TUBITAK (TUBITAK-BIDEB 2221-Fellowships for Visiting Scientists and Scientists on Sabbatical) for the postdoctoral fellowship). N.B. thanks EU FP7-Marie Curie-IRG for funding NEMSmart (PIRG05-GA-2009-249196). T.U. thanks EU FP7-Marie Curie-IRG (NANOWEB, PIRG06-GA-2009-256428) and The Turkish Academy of Sciences - Outstanding Young Scientists Award Program (TUBA-GEBIP) for partial funding. Authors thank M. Guler for technical support for TEM analysis.

\section{References}

1 W. J. Sweet, J. S. Jur and G. N. Parsons, J. Appl. Phys., 2013, 113, 194303.

2 C. J. Oldham, B. Gong, J. C. Spagnola, J. S. Jur, K. J. Senecal, T. A. Godfrey and G. N. Parsons, J. Electrochem. Soc., 2011, 158, D549-D556.

3 F. Kayaci, S. Vempati, C. O. Akgun, N. Biyikli and T. Uyar, Appl. Catal., B, 2014, 156-157, 173-183.

4 F. Kayaci, S. Vempati, I. Donmez, N. Biyikli and T. Uyar, Nanoscale, 2014, 6, 10224-10234.

5 F. Kayaci, S. Vempati, C. Ozgit, I. Donmez, N. Biyikli and T. Uyar, Nanoscale, 2014, 6, 5735.

6 P. Heikkilä, T. Hirvikorpi, H. Hilden, J. Sievänen, L. Hyvärinen, A. Harlin and M. Vähä-Nissi, J. Mater. Sci., 2012, 47, 3607-3612.

7 Q. Peng, X.-Y. Sun, J. C. Spagnola, G. K. Hyde, R. J. Spontak and G. N. Parsons, Nano Lett., 2007, 7, 719-722.

8 Q. Peng, X.-Y. Sun, J. C. Spagnola, C. Saquing, S. A. Khan, R. J. Spontak and G. N. Parsons, ACS Nano, 2009, 3, 546-554.

9 J. Y. Park, S.-W. Choi and S. S. Kim, Nanotechnology, 2010, 21, 475601.

10 S. Cho, D.-H. Kim, B.-S. Lee, J. Jung, W.-R. Yu, S.-H. Hong and S. Lee, Sens. Actuators, B, 2012, 162, 300-306.

11 E. Santala, M. Kemmel, M. Leskela and M. Ritala, Nanotechnology, 2009, 20, 035602. 
12 F. Kayaci, C. Ozgit-Akgun, N. Biyikli and T. Uyar, RSC Adv., 2013, 3, 6817-6820.

13 A. Celebioglu and T. Uyar, Chem. Commun., 2010, 46, 69036905.

14 A. Celebioglu and T. Uyar, Nanoscale, 2012, 4, 621-631.

15 A. Celebioglu and T. Uyar, J. Colloid Interface Sci., 2013, 404, $1-7$.

16 A. Celebioglu and T. Uyar, RSC Adv., 2013, 3, 22891-22895.

17 M. G. McKee, J. M. Layman, M. P. Cashion and T. E. Long, Science, 2006, 311, 353-355.

18 X. Yan, M. Zhou, J. Chen, X. Chi, S. Dong, M. Zhang, X. Ding, Y. Yu, S. Shaod and F. Huang, Chem. Commun., 2011, 47, 7086.

19 S. Ramakrishna, K. Fujihara, W. Teo, T. Lim and Z. Ma, An Introduction to Electrospinning and Nanofibers, World Scientific Publishing Company, Singapore, 2005.

$20 \mathrm{~J}$. H. Wendorff, S. Agarwal and A. Greiner, Electrospinning: Materials, Processing, and Applications, Wiley-VCH, Germany, 2012.
21 J. V. Nygaard, T. Uyar, M. Chen, P. Cloetens, P. Kingshott and F. Besenbacher, Nanoscale, 2011, 3, 3594-3597.

22 T. Uyar and F. Besenbacher, Polymer, 2008, 49, 5336-5343.

23 S. Vempati, S. Chirakkara, J. Mitra, P. Dawson, K. K. Nanda and S. B. Krupanidhi, Appl. Phys. Lett., 2012, 100, 162104.

24 S. Vempati, J. Mitra and P. Dawson, Nanoscale Res. Lett., 2012, 7, 470.

25 S. Vempati, A. Shetty, P. Dawson, K. K. Nanda and S. B. Krupanidhi, Thin Solid Films, 2012, 524, 137.

26 B. Díaz, E. Härkönen, J. Swiatowska, V. Maurice, A. Seyeux, P. Marcus and M. Ritala, Corros. Sci., 2011, 53, 2168-2175.

27 M. Chen, X. Wang, Y. H. Yu, Z. L. Pei, X. D. Bai, C. Sun, R. F. Huang and L. S. Wen, Appl. Surf. Sci., 2000, 158, 134140.

28 B. V. Crist, Handbooks of Monochromatic XPS Spectra: Commercially Pure Binary Oxides, XPS International, California, 2005, http//:www.xpsdata.com.

29 S. Major, S. Kumar, M. Bhatnagar and K. L. Chopra, Appl. Phys. Lett., 1986, 49, 394.

30 R. H. French, J. Am. Ceram. Soc., 1990, 73, 477-489. 